\title{
Frameless robot-assisted pallidal deep brain stimulation surgery in pediatric patients with movement disorders: precision and short-term clinical results
}

\author{
Santiago Candela, MD, 1,6 María Isabel Vanegas, MD, 2,6,7 Alejandra Darling, MD,, 2,6 \\ Juan Darío Ortigoza-Escobar, MD, PhD, 2,6 Mariana Alamar, MD, 1,6 Jordi Muchart, MD, 3,6 \\ Alejandra Climent, MD, 1,2,4,6 Enrique Ferrer, MD, PhD, ${ }^{1,5,6}$ Jordi Rumià, MD, 1,5,6 and \\ Belén Pérez-Dueñas, MD, PhD ${ }^{2,6,7}$
}

\begin{abstract}
Departments of ${ }^{1}$ Neurosurgery, ${ }^{2}$ Neuropediatrics, and ${ }^{3}$ Diagnostic Imaging, ${ }^{4}$ Intraoperative Neurophysiology Unit, and ${ }^{6}$ Pediatric Movement Disorders Unit, Sant Joan de Déu Barcelona Children's Hospital, Universitat de Barcelona; ${ }^{5}$ Department of Neurosurgery, Hospital Clinic de Barcelona, Universitat de Barcelona; and ${ }^{7}$ Vall d'Hebron Research Institute (VHIR), Universitat Autònoma de Barcelona, Barcelona, Catalonia, Spain
\end{abstract}

OBJECTIVE The purpose of this study was to verify the safety and accuracy of the Neuromate stereotactic robot for use in deep brain stimulation (DBS) electrode implantation for the treatment of hyperkinetic movement disorders in childhood and describe the authors' initial clinical results.

METHODS A prospective evaluation of pediatric patients with dystonia and other hyperkinetic movement disorders was carried out during the 1st year after the start-up of a pediatric DBS unit in Barcelona. Electrodes were implanted bilaterally in the globus pallidus internus (GPi) using the Neuromate robot without the stereotactic frame. The authors calculated the distances between the electrodes and their respective planned trajectories, merging the postoperative CT with the preoperative plan using VoXim software. Clinical outcome was monitored using validated scales for dystonia and myoclonus preoperatively and at 1 month and 6 months postoperatively and by means of a quality-of-life questionnaire for children, administered before surgery and at 6 months' follow-up. We also recorded complications derived from the implantation technique, "hardware," and stimulation.

RESULTS Six patients aged 7 to 16 years and diagnosed with isolated dystonia (DYT1 negative) (3 patients), choreodystonia related to PDE2A mutation (1 patient), or myoclonus-dystonia syndrome SGCE mutations (2 patients) were evaluated during a period of 6 to 19 months. The average accuracy in the placement of the electrodes was $1.24 \mathrm{~mm}$ at the target point. At the 6-month follow-up, patients showed an improvement in the motor (65\%) and functional (48\%) components of the Burke-Fahn-Marsden Dystonia Rating Scale. Patients with myoclonus and SGCE mutations also showed an improvement in action myoclonus (95\%-100\%) and in functional tests (50\%-75\%) according to the Unified Motor-Rating Scale. The Neuro-QOL score revealed inconsistent results, with improvement in motor function and social relationships but worsening in anxiety, cognitive function, and pain. The only surgical complication was medial displacement of the first electrode, which limited intensity of stimulation in the lower contacts, in one case.

CONCLUSIONS The Neuromate stereotactic robot is an accurate and safe tool for the placement of GPi electrodes in children with hyperkinetic movement disorders.

https://thejns.org/doi/abs/10.3171/2018.5.PEDS1814

KEYWORDS robotic arm; frameless; pediatric deep brain stimulation; movement disorders; dystonia; myoclonus dystonia syndrome; functional neurosurgery

ABBREVIATIONS AC = anterior commissure; BFMDRS = Burke-Fahn-Marsden Dystonia Rating Scale; DBS = deep brain stimulation; EEG = electroencephalographic; GPi = globus pallidus internus; MDS = myoclonus-dystonia syndrome; PC = posterior commissure; SEEG = stereoelectroencephalography; UMRS = Unified Myoclonus Rating Scale.

SUBMITTED January 4, 2018. ACCEPTED May 10, 2018.

INCLUDE WHEN CITING Published online July 20, 2018; DOI: 10.3171/2018.5.PEDS1814. 
$\mathrm{H}$ YPERKINETIC movement disorders encompass several inherited and acquired conditions that cause long-lasting motor disability in childhood. They are classified as dystonia, chorea, athetosis, myoclonus, tremor, tics, and stereotypies..$^{38}$ Dystonia is the most frequent hyperkinetic movement disorder in childhood, and it can occur in isolation or combined with other movement disorders (such as parkinsonism or myoclonus) or appear in children with a complex phenotype and associated neurological features. A few causative genetic defects have been described in isolated and combined dystonia syndromes, but for most patients the underlying genetic defect remains unknown. Despite the severe disability that is associated with generalized dystonia in childhood, no biologically based treatments are available for the majority of patients, because of the poor understanding of the pathophysiological mechanisms. Also, medications are often of limited efficacy and are accompanied by side effects.

In the last decade, clinical studies have reported beneficial effects of pallidal deep brain stimulation (DBS) in patients with generalized dystonia, ${ }^{11,21,41,43}$ especially when surgery is performed in the early stages before skeletal deformities occur. ${ }^{31}$ However, due to the limitation of pediatric movement disorder programs in many countries, most pediatric patients must wait until adulthood to receive surgery through adult programs. ${ }^{29}$

In our pediatric hospital a multidisciplinary Pediatric Movement Disorders Unit has been created, a DBS program has been developed to assist these patients, and a stereotactic robot for implantation of the brain electrodes has been acquired.

With the present study we aim to describe our initial experience in terms of accuracy of the robotic arm for the implantation of the electrodes and our short-term clinical results.

\section{Methods}

\section{Study Design and Patient Selection}

This is a 1-year prospective study of a cohort of patients treated by bilateral globus pallidus internus (GPi) DBS in our Pediatric Movement Disorders Unit between April 2016 and May 2017. Inclusion criteria for surgery were children aged 6 to 18 years affected by isolated or combined dystonia and not responding to medication, for whom a primary genetic condition was suspected. All patients underwent MRI studies that ruled out structural brain damage.

\section{Surgical Technique}

Preoperative MRI for direct localization of the posteroventral GPi was performed in all patients several days before surgery. The MRI study included volumetric acquisitions for neurosurgical navigation in $\mathrm{T} 1$ and $\mathrm{T} 2 \mathrm{se}-$ quences (Axial FSPGR BRAVO and CUBE T2) using a 1.5-T Signa MRI magnet (General Electric).

The MRI was loaded into the planning station. The anterior commissure (AC)-posterior commissure (PC) plane was defined to reformat the images in multiplanar reconstructions on the VoXim software (IVS Technology $\mathrm{GmbH})$. Recognition of the GPi boundaries on transverse axial sections was ensured, without referencing to an atlas or to the AC-PC line. Then, the target was chosen by using a 3D cursor vertically on the axial slice at the level of the AC, and horizontally at the junction between the 2 posterior quarters of the GPi. The $\mathrm{x}, \mathrm{y}$, and $\mathrm{z}$ coordinates were calculated automatically. The best electrode trajectory was selected in the anterolateral direction and was designed to be as vertical as possible, avoiding sulci, ventricles, and specially vessels. We checked the position of the contacts inside the GPi and confirmed that this projection touched the external border of the optic tract in the 3 planes. Definitive trajectories were transferred to the robotic arm working station.

Surgery was performed under general anesthesia and cefazolin antibiotic prophylaxis. The GPi electrodes and the implantable pulse generator (IPG) were implanted in the same surgical session.

Electrode insertion was assisted by the robotic arm Neuromate (Renishaw). For stereotactic spatial patient registration, a preoperative CT was acquired with a fiducial reference screwed to the patient's skull. Afterwards, the referenced CT was co-registered to the $3 \mathrm{D}$ previous MRI containing the planned trajectories using the VoXim software. The patient's head was stabilized with the 6-pin robotic arm head-holder. No stereotactic frame was employed. The co-registration was based on fiducial recognition and location through ultrasound (Fig. 1). A drill attached to the robotic arm was employed to create a groove in the cortical bone to ensure that the burr holes were exactly placed according to the presurgical plan, at the intersection between the trajectories and the cranium. Burr holes were made with a 14-mm drill (Codman ref. 26-1221). We inserted the quadripolar 3389 electrodes (Medtronic Neurological Division) to the appropriate depth through the way carved with a cannula (Medtronic ref. FC1019) attached to the 1.8-mm guide provided by Renishaw, and we locked them with the Stimloc (Medtronic).

Later, we performed electrical stimulation through the electrode according to therapeutic parameters and registered free-running electromyography (EMG) and cortical visual activity through electroencephalographic (EEG) recordings (Fig. 2). No microelectrode register was performed. Then we tunneled the connectors to the right retroauricular region.

Finally, we inserted the connecting leads $90 \mathrm{~cm}$ in length (Medtronic) and the IPG (Activa RC neurostimulator, Medtronic) in the abdominal wall after removing the head holder and repositioning the patient. Impedances were checked and a postoperative CT (still under general anesthesia) was performed in all patients just after the surgery.

The surgical technique is shown in Video 1.

VIDEO 1. DBS surgery assisted with the Neuromate robotic arm: surgical technique. Copyright Sant Joan de Déu Barcelona Children's Hospital. Published with permission. Click here to view.

\section{Accuracy}

We determined system accuracy by calculating distances between the electrodes and their respective planned trajectories. To do this, we merged the postoperative CT with the preoperative plan using the VoXim software and used measuring tools provided by this software (Fig. 3). 


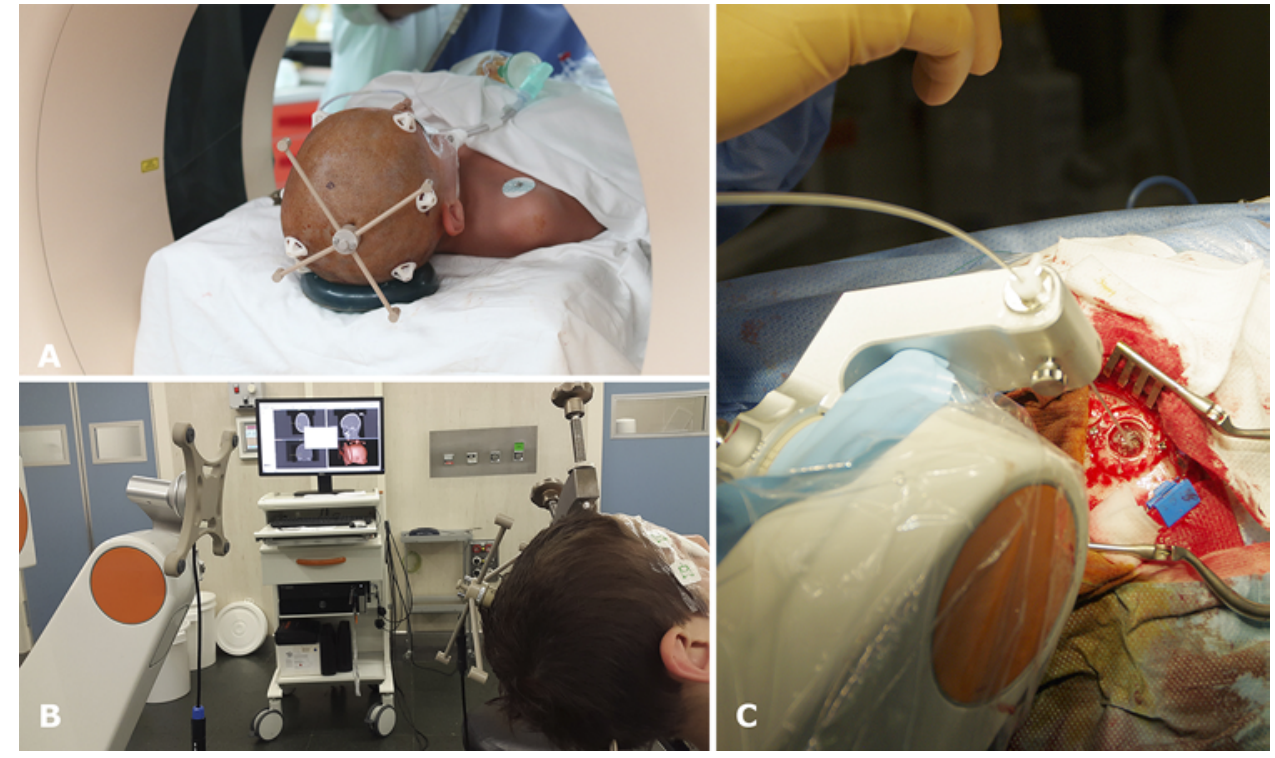

FIG. 1. A: Fiducial reference screwed to patient's skull for CT localization. B: Ultrasound registration by the robotic arm. C: Electrode insertion through the previously carved path with a stylet supported by the robot. Figure is available in color online only.

\section{Outcome Assessment}

Patients with dystonia were evaluated using the BurkeFahn-Marsden Dystonia Rating Scale (BFMDRS) preoperatively and 1 and 6 months postoperatively. ${ }^{6}$ In patients with myoclonus-dystonia, we used the BFMDRS for dystonic features and the Unified Myoclonus Rating Scale $(\mathrm{UMRS})^{14}$ for the rating of myoclonic jerks preoperatively and 1 and 6 months after the surgery. Quality of life was evaluated with the pediatric Neuro-QOL ${ }^{22}$ preperatively and 6 months after the surgery. All patients were videotaped for evaluation by movement disorder experts (B.P.D., M.I.V.) before surgery and 1 month and 6 months after surgery.

\section{Approval}

All participants or their legal guardians provided informed consent for their inclusion in the study. All procedures followed the Declaration of Helsinki, 1975, as revised in 2013. The study was approved by the Research and Ethics Committee of Sant Joan de Déu Barcelona Hospital.

\section{Results}

\section{Patients}

Six patients were treated with GPi stimulation during the study period. Their mean age at intervention was 11.8 years (range 7-16 years), and their mean disease duration was 7 years (range $0.5-12$ years).

Patients 1,3, and 5 presented with lower limb dystonia at a mean age of 6.8 years, and all showed isolated generalized dystonia at the time of intervention. Testing with a multi-gene panel including all genes known to be linked to dystonia yielded normal results for these patients.

Patients 2 and 4 had suffered from myoclonus-dystonia syndrome (MDS) since the age of 3 years. Both had pathogenic variants of the $S G C E$ gene.

Patient 6 with prominent choreo-dystonia and paroxys- mal attacks of dyskinesia had mutations in $P D E 2 A$, a gene recently linked to chorea in childhood. ${ }^{37}$

In all 6 cases, the patients' symptoms had been refractory to the pharmacological treatment used for movement disorders. Patient 3 had prominent dysarthria and laryngeal dysphonia. No other neurological features were observed on examination of the other patients. Cognitive assessment performed at baseline disclosed normal results in all patients except patient 6 , who was affected by moderate cognitive disability (Kauffman Brief Intelligence Test total score 44). Psychiatric assessment identified obsessive-compulsive behavior, anxiety, and depression in patients 2 and 4 (who both had MDS).

Table 1 summarizes the demographic, clinical, and genetic data for the 6 patients.

\section{Location of Electrodes}

The resulting stereotactic coordinates of direct visualization of the posteroventral GPi in the MRI in our patients, presented as mean (range), were $\mathrm{x}, 18.6$ (17.5-20.5); $y, 2.25(2-2.5) ; z,-4$ (-3 to -6$)$. The mean accuracy in the placement of the electrodes was $1.2 \mathrm{~mm}$ at the target point and $1.9 \mathrm{~mm}$ at the entry point (Table 2). The mean surgical time was 8 hours 5 minutes (range 7 hours 35 minutes to 8 hours 44 minutes).

\section{Stimulation Settings}

We began stimulation within the first 48 hours after the surgery. We started with monopolar stimulation in the lower contacts, voltage intensity $10 \%-20 \%$ below the threshold of appearance of secondary effects, $60 \mu \mathrm{sec}, 130$ $\mathrm{Hz}$. Parameters were adjusted according to the clinical response (Table 3).

\section{Outcome}

Tables 4 and 5 describe the changes in dystonia and 

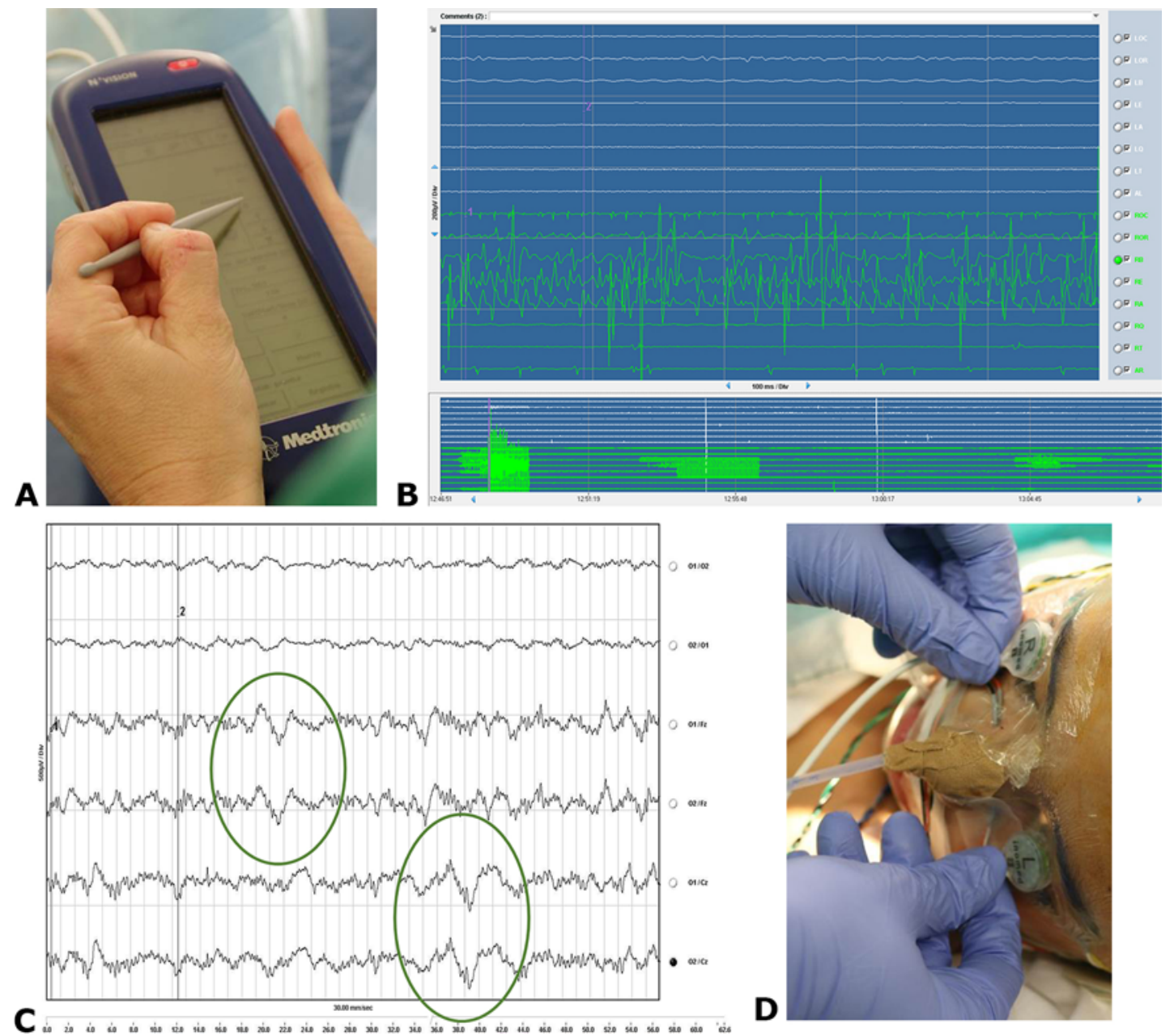

FIG. 2. A: Stimulation according to the therapeutic parameters using the N'Vision (Medtronic). B: Electromyographic activity in biceps, common extensor digitorum, and right thumb abductor after stimulation of the left pallidal electrode $([0-1+] 6 \mathrm{~V}, 90 \mu \mathrm{sec}$, $180 \mathrm{~Hz}$ ). C: Baseline EEG recording in occipital electrodes in which the visual evoked potential (VEP) is appreciated by stimulating the pallidal electrode at the level of the contacts on the optic tract (0-1+). D: Application of red light LED lenses for optical stimulation. Figure is available in color online only.

myoclonus according to the BFMDRS and UMRS in a 6-month follow-up period. Presurgical and postsurgical quality-of-life values measured with Neuro-QOL are detailed in Table 5.

We observed a significant improvement in the motor $(65 \% \pm 29 \%)$ and functional $(48 \% \pm 38 \%)$ components of the BFMDRS in the whole study cohort at the 6-month follow-up period. The 2 patients with myoclonus and SGCE mutations also showed an improvement in action myoclonus $(95 \%-100 \%)$ and in functional tests $(50 \%-$ $75 \%$ ) according to the UMRS. Individually, all patients showed a significant improvement with the exception of patient 6 with choreo-dystonia due to PDE2A deficiency, who improved in the first weeks after DBS, but the response was not sustained, and the BFMDRS scores at 6 months showed a very mild improvement in his dystonic features without functional amelioration. All patients were able to withdraw from antidystonic medication, with the exception of patient 4 who was still receiving treatment with trihexyphenidyl at the time of the study.
The pediatric Neuro-QOL showed an improvement in upper and lower limb function, stigma, social relationships, and anger items, with no change in depression score. However, we observed worsening in anxiety, fatigue, cognitive function, and pain.

Video 2 shows detailed evolution of some clinical features, including dystonia and other hyperkinetic movements, in the 6 patients before and after DBS.

VIDEO 2. Video clips obtained before and at 1 and 6 months after surgery showing some clinical features of the patients' dystonia and other hyperkinetic movements. Copyright Sant Joan de Déu Barcelona Children's Hospital. Published with permission. Click here to view.

\section{Adverse Events}

The only intraoperative complication was medial tip deviation $(4 \mathrm{~mm})$ of the first electrode we implanted in patient 1 .

Transient dysarthria was observed in patients 1 and 4 . Stimulation-induced hypokinesia with freezing of gait, 


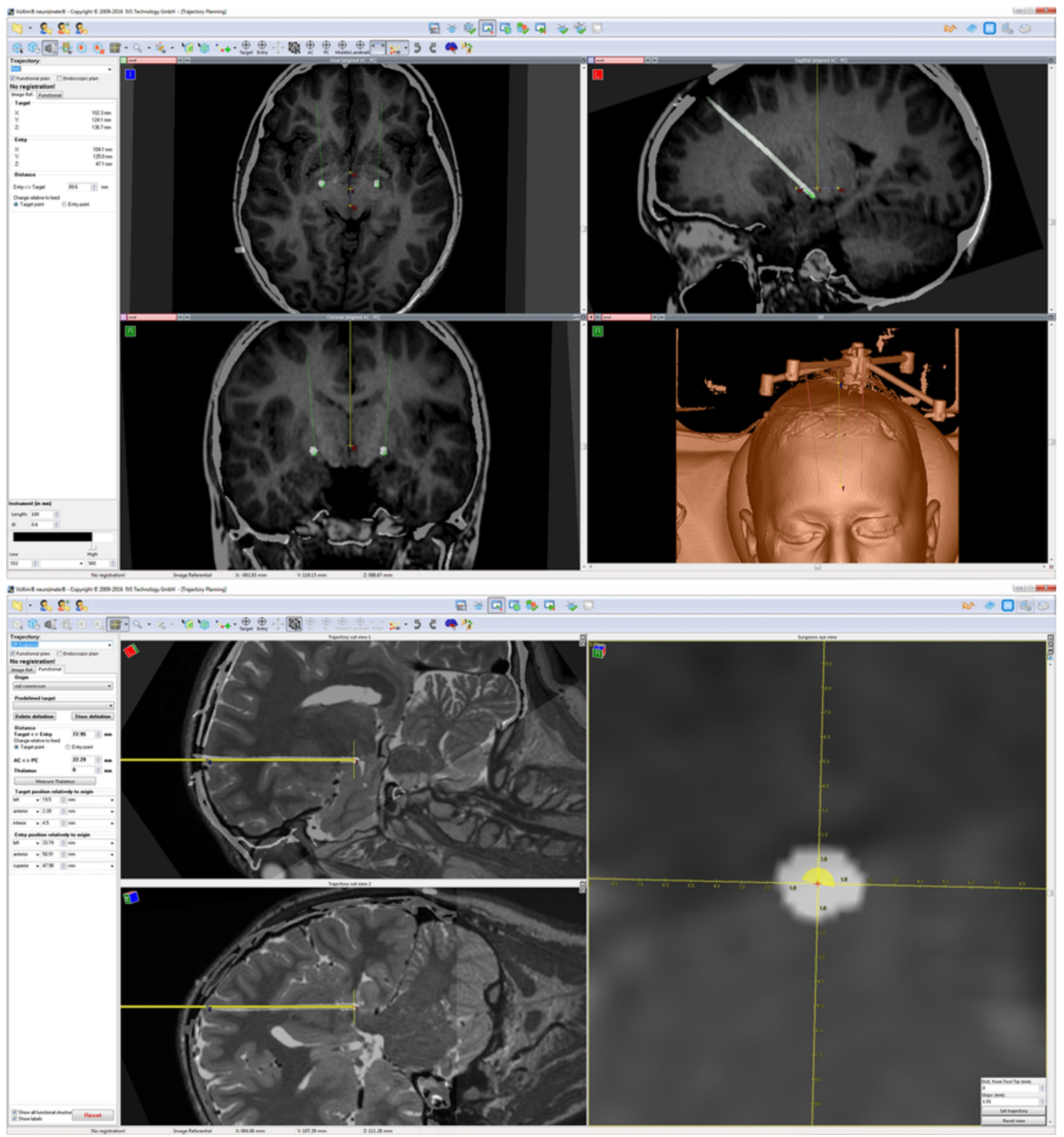

FIG. 3. Screenshots showing electrodes location (upper) and precision measurement (lower) both through the VoXim software. Figure is available in color online only.

unstable gait, and micrographia was observed in patient 3 at the following settings: $3(-) 0(+), 3 \mathrm{~V}, 90 \mu \mathrm{sec}, 180 \mathrm{~Hz}$; $9(-) 7(+), 3 \mathrm{~V}, 90 \mu \mathrm{sec}, 180 \mathrm{~Hz}$. These side effects disappeared after the frequency of stimulation was reduced to $90 \mathrm{~Hz}$. Patient 4 showed a sudden clinical worsening of myoclonus due to the accidental shutdown of her neurostimulator.

None of the remaining patients experienced any further complication or serious adverse effect due to DBS.

\section{Discussion}

Pallidal DBS is a technique of proven effectiveness and safety for the treatment of dystonia in adults ${ }^{11,20,21,41,43}$ and children. . $, 8,15,17,18,33,35,40$ It has also been used to treat lifethreatening conditions such as status dystonicus. ${ }^{3,10}$ Our previous experience with surgery for the treatment of dystonia was described in an earlier publication by Valldeoriola et al. ${ }^{41}$

In order to offer this treatment to pediatric patients in our country, we have created a Pediatric Multidisciplinary Movement Disorders Unit and have initiated a DBS Program. Since we did not have a stereotactic frame and the development of our program coincided with the rise of the stereoelectroencephalography (SEEG) indication in our center, we decided to acquire the stereotactic robot to use in both techniques.

Although the use of robotics is spreading in neurosur- 
TABLE 1. Summary of demographic, clinical, and genetic data for the study cohort

\begin{tabular}{cccclll}
\hline Pt No. & $\begin{array}{c}\text { Age at DBS } \\
\text { (yrs) }\end{array}$ & $\begin{array}{c}\text { Age at Sx Onset } \\
\text { (yrs) }\end{array}$ & Sex & Clinical Dx & Genotype & Medication Before DBS \\
\hline 1 & 9 & 4 & M & Primary dystonia & Unknown* & Diazepam, trihexyphenidyl \\
\hline 2 & 14 & 3 & F & MDS & SGCE c.733_737delAATT (exon 6) & Levodopa, trihexyphenidyl \\
\hline 3 & 16 & 10 & M & Primary dystonia & Unknown* & Trihexyphenidyl \\
\hline 4 & 15 & 3 & F & MDS & SGCE c.627_628insGGGGTGGC (exon 5) & Diazepam, trihexyphenidyl \\
\hline 5 & 7 & 6.5 & F & Primary dystonia & Unknown* & Levodopa, botulinum toxin \\
\hline 6 & 11 & 2.5 & M & Choreo-dystonia & PDE2A, c.1439A>G; homozygous for p.Asp480Gly & Carbamazepine \\
\hline
\end{tabular}

Dx = diagnosis; $M D S$ = myoclonus-dystonia syndrome; $\mathrm{pt}=$ patient; $\mathrm{Sx}=$ symptom.

* The results of testing with a gene panel that included dystonia-related genes were negative in these patients.

gery, there have been only a few cases reported in children. $^{12,30,45}$ To date, many surgeons have used robots for stereotaxy in epilepsy surgery with adult patients and combined in combination with the use of a stereotactic frame. However, we report the largest pediatric neurosurgical experience with robot-assisted GPi DBS surgery in children with primary hyperkinetic movement disorders.

The accuracy obtained in our patients at the target point was similar to that reported by other groups with other frameless stereotaxic systems $(0.86-2.5 \mathrm{~mm})^{7,12,13,42}$ but slightly inferior to the in vitro accuracy of the Neuromate robot $(0.44 \mathrm{~mm})^{44}$ and to accuracy achieved with framebased systems $(1.2 \mathrm{~mm}) .{ }^{4}$ Our results support the effectiveness, accuracy, and safety of this technique, and according to our experience, obviate the need for a stereotaxic frame, at least to the point that it would not be necessary to obtain one if a hospital does not already have one. There are some particularities when using the stereotactic robot for the implantation of DBS electrodes in the pediatric population that must be underlined. The first point refers to the targeting point of stimulation. We performed direct targeting of the GPi in preoperative MRI. When we analyzed our stereotactic coordinates, we realized that the $\mathrm{x}$ coordinate was 1-2 $\mathrm{mm}$ more medial in our patients than in most published series. ${ }^{15,19}$ This is probably due to the fact that our patients are exclusively pediatric. Nevertheless, transient dysarthria in patients 1 and 4 could reflect proximity of the electrodes to the internal capsule, although it was only confirmed with respect to patient 1 in the lower contacts of the misplaced electrode lead in which stimulation thresholds were reduced. It will be necessary to undertake long- term monitoring of stimulation complications due to this more medial placement in our series.

The second point refers to the age of children selected for surgery. The youngest patient in our series was 7 years old. Although we have used the robotic arm in SEEG electrode placement procedures in patients as young as 5 years, the youngest patient in our DBS series was 7 years old, and we believe that bone thickness and nutritional status should be considered in order to prevent skin ulceration and infection. In fact, in younger children with a poor nutritional state who require DBS surgery due to the severity of their disease, subfascial placement of the neurostimulator could be considered. Moreover, brain growth following electrode implantation may also result in relative retraction of contact positions compared to the original target position. Brain growth has been previously modeled, suggesting a relative retraction of the brain electrodes of between 5 and $10 \mathrm{~mm}$ between 4 and 18 years of age, mostly occurring before 5 years of age and a little between 5 and 7 years. ${ }^{24}$

The third point is the use of general anesthesia in pediatric patients. In adult patients, surgery is performed with the patient awake, if the severity of dystonia allows it. Although some authors also operate on pediatric patients while the patients are awake, ${ }^{29}$ we prefer to do it under general anesthesia. For this reason, we perform intraoperative neurophysiological tests (described under Surgical Technique) in order to determine if the electrode is close to the optic tract and its proximity to internal capsule.

Finally, the young age of our patients and the high voltage needed for the treatment of dystonia made us decide

TABLE 2. Stereotactic coordinates resulting on direct targeting on the MRI and precision of the Neuromate calculated with VoXim software

\begin{tabular}{|c|c|c|c|c|c|c|c|c|c|}
\hline \multirow[b]{2}{*}{ Pt No. } & \multirow[b]{2}{*}{ AC-PC* } & \multicolumn{3}{|c|}{ Stereotactic Coordinates } & \multicolumn{2}{|c|}{ Entry Deviation (mm) } & \multicolumn{2}{|c|}{ Target Deviation (mm) } & \multirow[b]{2}{*}{ Surgical Time } \\
\hline & & $x$ & $y$ & z & Right & Left & Right & Left & \\
\hline 1 & 21.73 & 20.5 & 2 & -3 & 3.8 & 1.6 & 4 & 1.2 & $7 \mathrm{hrs}, 40 \mathrm{mins}$ \\
\hline 2 & 22.5 & 17.5 & 2.5 & -6 & 3 & 3 & 1.2 & 1.4 & $7 \mathrm{hrs}, 35 \mathrm{mins}$ \\
\hline 3 & 21.19 & 18 & 2.5 & -3.5 & 0.45 & 3 & 1.2 & 0.2 & $8 \mathrm{hrs}, 40 \mathrm{mins}$ \\
\hline 4 & 22.29 & 19.5 & 2 & -4.5 & 0.7 & 1.3 & 0.9 & 0.2 & $8 \mathrm{hrs}, 44 \mathrm{mins}$ \\
\hline 5 & 23.04 & 18.5 & 2.5 & -3 & 2.3 & 1.5 & 2.2 & 1 & $8 \mathrm{hrs}$ \\
\hline 6 & 21.26 & 18 & 2 & -4 & 1 & 1.1 & 0.85 & 0.6 & $7 \mathrm{hrs}, 55 \mathrm{mins}$ \\
\hline Mean & 22 & 18.6 & 2.2 & -4 & \multicolumn{2}{|c|}{1.8} & \multicolumn{2}{|c|}{1.24} & $8 \mathrm{hrs}, 5 \mathrm{mins}$ \\
\hline
\end{tabular}

${ }^{*}$ AC-PC distance in millimeters. 
TABLE 3. Stimulation settings at last follow-up

\begin{tabular}{clc}
\hline Pt No. & \multicolumn{1}{c}{ Left Hemisphere } & \multicolumn{1}{c}{ Right Hemisphere } \\
\hline 1 & $3(-), 2 \mathrm{~V}, 60 \mu \mathrm{sec}, 180 \mathrm{~Hz}$ & $8(-), 3.8 \mathrm{~V}, 60 \mu \mathrm{sec}, 180 \mathrm{~Hz}$ \\
\hline 2 & $0(-), 2.8 \mathrm{~V}, 60 \mu \mathrm{sec}, 180 \mathrm{~Hz}$ & $8(-), 3.3 \mathrm{~V}, 60 \mu \mathrm{sec}, 180 \mathrm{~Hz}$ \\
\hline 3 & $3(-) 0(+), 3 \mathrm{~V}, 90 \mu \mathrm{sec}, 90 \mathrm{~Hz}$ & $9(-) 7(+), 3 \mathrm{~V}, 90 \mu \mathrm{sec}, 90 \mathrm{~Hz}$ \\
\hline 4 & $2(-), 3 \mathrm{~V}, 90 \mu \mathrm{sec}, 130 \mathrm{~Hz}$ & $9(-), 2.5 \mathrm{~V}, 90 \mu \mathrm{sec}, 130 \mathrm{~Hz}$ \\
\hline 5 & $0(-), 3.2 \mathrm{~V}, 90 \mu \mathrm{sec}, 150 \mathrm{~Hz}$ & $8(-), 3.6 \mathrm{~V}, 90 \mu \mathrm{sec}, 150 \mathrm{~Hz}$ \\
\hline 6 & $9(-) 11(+), 2.5 \mathrm{~V}, 60 \mu \mathrm{sec}$, & $0(-) 2(+), 2.5 \mathrm{~V}, 60 \mu \mathrm{sec}$, \\
& $200 \mathrm{~Hz}$ & $200 \mathrm{~Hz}$ \\
\hline
\end{tabular}

to use rechargeable neurostimulators in all cases. ${ }^{27} \mathrm{Re}$ chargeable neurostimulators reduce not only the number of stimulator change surgeries but also the associated risk of infection. Moreover, we inserted the neurostimulator in the abdomen and used long connection wires $(90 \mathrm{~cm})$ because of the expected growth in these children.

The mean surgical time was 8 hours, which is slightly longer than in other reported robotic series. ${ }^{12}$ Our long sur- gical time is probably due to our learning curve, to the time spent in transferring the patient to the CT facility twice (first to perform the CT with the fiducial and then to check accuracy postoperatively), to the intraoperative neurophysiological tests (electrical stimulation through the electrode and registration of electromyography and cortical visual activity through electroencephalographic recordings), and also to the time required for the implantation of the neurostimulator and the connection wires. In order to shorten surgical time, an intraoperative $\mathrm{CT}^{7}$ or $\mathrm{MRI}^{39}$ is mandatory, together with increasing the expertise of the surgical team.

The benefits of this therapy seem to be clear. Motor scores for dystonia and myoclonus improved 62\%-83\% and $95 \%-100 \%$, respectively, and functional impairment improved in parallel with the motor improvement in dystonic $(42 \%-65 \%)$ and myoclonic $(50 \%-75 \%)$ patients. Also, in 5 of 6 cases the patients were able to discontinue antidystonic and antimyoclonic medication.

Dystonia in childhood is more commonly a symptomatic condition, with dystonia frequently expressed on the

TABLE 4. Change in dystonia and myoclonus measured with BFMDRS and UMRS in the study cohort: values for each patient

\begin{tabular}{|c|c|c|c|c|c|c|c|c|c|}
\hline \multirow[b]{2}{*}{ Scale \& Pt No. } & \multirow[b]{2}{*}{ Time Point } & \multicolumn{4}{|c|}{ Score } & \multicolumn{4}{|c|}{ Improvement (\%) } \\
\hline & & Motor* & Actiont & Function & Total & Motor* & Actiont & Function & Total \\
\hline \multicolumn{10}{|l|}{ BFMDRS } \\
\hline \multirow{3}{*}{1} & Pre-DBS & 41 & NA & 17 & 58 & NA & NA & NA & NA \\
\hline & 1 mo postop & 11.5 & NA & 8 & 19.5 & 72 & NA & 53 & 66 \\
\hline & 6 mos postop & 7 & NA & 6 & 13 & 83 & NA & 65 & 78 \\
\hline \multirow{3}{*}{2} & Pre-DBS & 14 & NA & 2 & 16 & NA & NA & NA & NA \\
\hline & 1 mo postop & 3 & NA & 1 & 4 & 79 & NA & 50 & 75 \\
\hline & 6 mos postop & 1 & NA & 0 & 1 & 93 & NA & 100 & 94 \\
\hline \multirow{3}{*}{3} & Pre-DBS & 54.5 & NA & 12 & 66.5 & NA & NA & NA & NA \\
\hline & 1 mo postop & 35.5 & NA & 10 & 45.5 & 35 & NA & 17 & 32 \\
\hline & 6 mos postop & 20.5 & NA & 7 & 27.5 & 62 & NA & 42 & 59 \\
\hline \multirow{3}{*}{4} & Pre-DBS & 6 & NA & 5 & 11 & NA & NA & NA & NA \\
\hline & 1 mo postop & 3 & NA & 3 & 6 & 50 & NA & 40 & 45 \\
\hline & 6 mos postop & 2 & NA & 3 & 5 & 67 & NA & 40 & 56 \\
\hline \multirow{3}{*}{5} & Pre-DBS & 40 & NA & 7 & 47 & NA & NA & NA & NA \\
\hline & 1 mo postop & 20.5 & NA & 4 & 24.5 & 35 & NA & 17 & 48 \\
\hline & 6 mos postop & 9 & NA & 3 & 12 & 78 & NA & 57 & 74 \\
\hline \multirow{3}{*}{6} & Pre-DBS & 34.5 & NA & 12 & 46.5 & NA & NA & NA & NA \\
\hline & 1 mo postopł & - & NA & - & - & - & NA & - & - \\
\hline & 6 mos postop & 31 & NA & 14 & 45 & 10 & NA & 0 & 10 \\
\hline \multicolumn{10}{|l|}{ UMRS } \\
\hline \multirow{3}{*}{2} & Pre-DBS & NA & 19 & 8 & 50 & NA & NA & NA & NA \\
\hline & 1 mo postop & NA & 3 & 3 & 10 & NA & 84 & 62 & 80 \\
\hline & 6 mos postop & NA & 1 & 2 & 3 & NA & 95 & 75 & 94 \\
\hline \multirow{3}{*}{4} & Pre-DBS & NA & 28 & 10 & 72 & NA & NA & NA & NA \\
\hline & 1 mo postop & NA & 1 & 6 & 29 & NA & 96 & 40 & 60 \\
\hline & 6 mos postop & NA & 0 & 5 & 18 & NA & 100 & 50 & 75 \\
\hline
\end{tabular}

$\mathrm{NA}=$ not applicable; $-=$ not available.

* For BFMDRS only.

† For UMRS only.

$\ddagger$ This patient came from another country and did not return for 1-month follow-up 
TABLE 5. Change in dystonia, myoclonus, and quality of life, measured with BFMDRS, UMRS, and Neuro-QOL respectively, in the study cohort of patients with isolated dystonia and myoclonus dystonia: aggregated results

\begin{tabular}{|c|c|c|c|c|c|}
\hline \multirow[b]{2}{*}{ Measure } & \multirow[b]{2}{*}{ Pre-DBS } & \multicolumn{2}{|c|}{$1 \mathrm{Mo}$ Post-DBS } & \multicolumn{2}{|c|}{6 Mos Post-DBS } \\
\hline & & Score & Change & Score & Change \\
\hline \multicolumn{6}{|l|}{ BFMDRS* } \\
\hline Motor & $32 \pm 18$ & $15 \pm 14$ & Impr: $57 \pm 18 \%$ & $12 \pm 11$ & Impr: $65 \pm 29 \%$ \\
\hline Function & $10 \pm 5$ & $5 \pm 4$ & Impr: $40 \pm 14 \%$ & $6 \pm 5$ & Impr: $48 \pm 38 \%$ \\
\hline Total & $40 \pm 22$ & $20 \pm 18$ & Impr: $53 \pm 17 \%$ & $17 \pm 16$ & Impr: $60 \pm 31 \%$ \\
\hline \multicolumn{6}{|l|}{ UMRS† } \\
\hline Action myoclonus & 19,28 & 3,1 & Impr: $84 \%, 96 \%$ & 1,0 & Impr: 95\%, 100\% \\
\hline Functional test & 8,10 & 3,6 & Impr: $62 \%, 40 \%$ & 2,5 & Impr: $75 \%, 50 \%$ \\
\hline Total score & 50,72 & 10,29 & Impr: $80 \%, 60 \%$ & 3,18 & Impr: 94\%, 75\% \\
\hline \multicolumn{6}{|l|}{ Neuro-QOL $\ddagger$} \\
\hline UL function & $68 \pm 12$ & - & - & $70 \pm 11$ & $+4 \%$ (impr) \\
\hline LL function & $61 \pm 10$ & - & - & $68 \pm 11$ & $+11 \%$ (impr) \\
\hline Anxiety & $16 \pm 6$ & - & - & $18 \pm 13$ & $+11 \%$ (worse) \\
\hline Stigma & $19 \pm 10$ & - & - & $16 \pm 13$ & $-9 \%$ (impr) \\
\hline Fatigue & $16 \pm 4$ & - & - & $18 \pm 9$ & $+6 \%$ (worse) \\
\hline Depression & $17 \pm 12$ & - & - & $16 \pm 13$ & $0 \%(\mathrm{NC})$ \\
\hline Cognitive & $34 \pm 9$ & - & - & $32 \pm 7$ & $-4 \%$ (worse) \\
\hline Social relation & $31 \pm 13$ & - & - & $32 \pm 12$ & $+9 \%$ (impr) \\
\hline Anger & $25 \pm 9$ & - & - & $19 \pm 12$ & $-14 \%$ (impr) \\
\hline Pain & $26 \pm 17$ & - & - & $26 \pm 16$ & $+11 \%$ (worse) \\
\hline
\end{tabular}

background of a structurally abnormal brain. Outcomes following DBS in this setting are much more variable, for reasons that have yet to be elucidated. Much of the focus on improving outcomes following DBS in dystonia management has related to the importance of patient selection ${ }^{23}$ as well as the target. Overall, an extensive bibliography suggests that patients affected by neurodegenerative dystonia ${ }^{2}$ or other secondary dystonias ${ }^{33}$ do not respond as well as patients affected by monogenic dystonia ${ }^{1}$ or myoclonic dystonia. ${ }^{9,36}$ Also, the use of GPi DBS has been demonstrated to be more effective than other DBS to other targets for isolated dystonia and MDS. ${ }^{25}$

Although patients and family members as well as health professionals had the subjective perception of a significant improvement in quality of life, we obtained inconsistent results with the pediatric Neuro-QOL 6 months after surgery. As described in Table 5, an improvement was observed in upper and lower limb function, stigma, social relationships, and anger items, with no change in depression score. However patients reported a worsening in scales of anxiety, fatigue, pain, and cognitive function. These inconsistent results are probably influenced by the mood of the children at the time of assessment or by the patient's high expectations of faster short-term improvement. In addition, patients 2 and 4 had psychiatric comorbidities (depression, anxiety) and were were still receiving pharmacological treatment (trihexyphenidyl, diazepam) that might have negatively influenced some items like cog- nitive function. We believe that longer follow-up is needed to test the improvement in quality of life using the NeuroQOL scale.

We performed an additional pre-DBS and post-DBS neuropsychological evaluation in patients 1 to 5. No signs of cognitive deterioration were recorded; in fact, we observed an improvement in processing speed and working memory, probably related to the withdrawal of anticholinergics and benzodiazepines. Further research in this field is an important goal as cognitive implications of DBS in the developing brain are still unknown. ${ }^{34}$

We only had a single intraoperative complication, consisting of medial tip deviation of the first electrode we implanted $(4 \mathrm{~mm})$. This happened because we left the cannula $1 \mathrm{~cm}$ above the target in order to avoid artifact stimulation through the electrode when doing the neurophysiological tests. As the electrode is flexible, it curved when going deep until the target. We solved this electrode malposition by stimulating through the third contact with excellent response, so we did not relocate this electrode. When we inserted all the other electrodes we positioned the cannula directly to the target and this problem was avoided.

In our follow-up we did not have any infectious complication despite the young age of patients (under the age of 9 years in 3 cases). The risk of hardware-related complications in children under 9 years of age is controversial. ${ }^{17,18}$ However, the outcome is better when patients are younger and disease duration is shorter. ${ }^{15,16,26,36}$ These are impor- 
tant reasons to perform these surgeries in hospitals that are dedicated to children and include specialized pediatric movement disorder units. ${ }^{17}$

\section{Conclusions}

This brief report demonstrates that the Neuromate stereotactic robot is an accurate tool for the placement of internal pallid electrodes in children with movement disorders. We also describe our first clinical results in a small sample of patients and show that GPi DBS is an effective and safe technique for the treatment of dystonia and myoclonus in pediatric patients. High efficacy in our series is a consequence of not only the accuracy of the placement of the electrodes, but also the selection of the appropriate target, programming parameters for stimulation, and the underlying pathology causing dystonia, all our patients being affected by primary isolated or combined forms of dystonia. However, some limitations of this study include the brief follow-up period and the absence of a blind evaluation of the results. Furthermore, a longer follow-up is needed to rule out the risk of tolerance ${ }^{32}$ or electrode migration with growth. ${ }^{24} \mathrm{We}$ expect to analyze the longterm results of this cohort of patients and to participate in cooperative multicenter blind studies in the near future. ${ }^{28}$

\section{Acknowledgments}

We thank Carles Fàbrega Agullo and Gemma Fernandez Asensio for figures and video editing.

\section{References}

1. Aravamuthan BR, Waugh JL, Stone SS: Deep brain stimulation for monogenic dystonia. Curr Opin Pediatr 29:691696, 2017

2. Beaulieu-Boire I, Aquino CC, Fasano A, Poon YY, Fallis M, Lang AE, et al: Deep brain stimulation in rare inherited dystonias. Brain Stimul 9:905-910, 2016

3. Ben-Haim S, Flatow V, Cheung T, Cho C, Tagliati M, Alterman RL: Deep brain stimulation for status dystonicus: a case series and review of the literature. Stereotact Funct Neurosurg 94:207-215, 2016

4. Bjartmarz H, Rehncrona S: Comparison of accuracy and precision between frame-based and frameless stereotactic navigation for deep brain stimulation electrode implantation. Stereotact Funct Neurosurg 85:235-242, 2007

5. Borggraefe I, Mehrkens JH, Telegravciska M, Berweck S, Bötzel K, Heinen F: Bilateral pallidal stimulation in children and adolescents with primary generalized dystonia--report of six patients and literature-based analysis of predictive outcomes variables. Brain Dev 32:223-228, 2010

6. Burke RE, Fahn S, Marsden CD, Bressman SB, Moskowitz $\mathrm{C}$, Friedman J: Validity and reliability of a rating scale for the primary torsion dystonias. Neurology 35:73-77, 1985

7. Cardinale F, Rizzi M, d'Orio P, Casaceli G, Arnulfo G, Narizzano M, et al: A new tool for touch-free patient registration for robot-assisted intracranial surgery: application accuracy from a phantom study and a retrospective surgical series. Neurosurg Focus 42E8, 2017

8. Cif L, Coubes P: Historical developments in children's deep brain stimulation. Eur J Paediatr Neurol 21:109-117, 2017

9. Cif L, Valente EM, Hemm S, Coubes C, Vayssiere N, Serrat $\mathrm{S}$, et al: Deep brain stimulation in myoclonus-dystonia syndrome. Mov Disord 19:724-727, 2004

10. Coubes P, Echenne B, Roubertie A, Vayssière N, Tuffery S, Humbertclaude V, et al: Traitement de la dystonie générali- sée à début précoce par stimulation chronique bilatérale des globus pallidus internes. A propos d'un cas. Neurochirurgie 45:139-144, 1999

11. Coubes P, Roubertie A, Vayssiere N, Hemm S, Echenne B: Treatment of DYT1-generalised dystonia by stimulation of the internal globus pallidus. Lancet 355:2220-2221, 2000

12. De Benedictis A, Trezza A, Carai A, Genovese E, Procaccini $\mathrm{E}$, Messina R, et al: Robot-assisted procedures in pediatric neurosurgery. Neurosurg Focus 42:E7, 2017

13. Eljamel MS: Robotic neurological surgery applications: accuracy and consistency or pure fantasy? Stereotact Funct Neurosurg 87:88-93, 2009

14. Frucht SJ, Leurgans SE, Hallett M, Fahn S: The unified myoclonus rating scale. Adv Neurol 89:361-376, 2002

15. Haridas A, Tagliati M, Osborn I, Isaias I, Gologorsky Y, Bressman SB, et al: Pallidal deep brain stimulation for primary dystonia in children. Neurosurgery 68:738-743, discussion 743, 2011

16. Isaias IU, Volkmann J, Kupsch A, Burgunder JM, Ostrem JL, Alterman RL, et al: Factors predicting protracted improvement after pallidal DBS for primary dystonia: the role of age and disease duration. J Neurol 258:1469-1476, 2011

17. Kaminska M, Perides S, Lumsden DE, Nakou V, Selway R, Ashkan K, et al: Complications of Deep Brain Stimulation (DBS) for dystonia in children - the challenges and 10 year experience in a large paediatric cohort. Eur J Paediatr Neurol 21:168-175, 2017

18. Koy A, Weinsheimer M, Pauls KAM, Kühn AA, Krause $\mathrm{P}$, Huebl J, et al : German registry of paediatric deep brain stimulation in patients with childhood-onset dystonia (GEPESTIM). Eur J Paediatr Neurol 21:136-146, 2017

19. Krause M, Fogel W, Kloss M, Rasche D, Volkmann J, Tronnier V: Pallidal stimulation for dystonia. Neurosurgery 55:1361-1368, discussion 1368-1370, 2004

20. Krauss JK, Pohle T, Weber S, Ozdoba C, Burgunder JM: Bilateral stimulation of globus pallidus internus for treatment of cervical dystonia. Lancet 354:837-838, 1999

21. Kupsch A, Benecke R, Müller J, Trottenberg T, Schneider $\mathrm{GH}$, Poewe W, et al : Pallidal deep-brain stimulation in primary generalized or segmental dystonia. N Engl J Med 355:1978-1990, 2006

22. Lai JS, Nowinski C, Victorson D, Bode R, Podrabsky T, McKinney N, et al: Quality-of-life measures in children with neurological conditions: pediatric Neuro-QOL. Neurorehabil Neural Repair 26:36-47, 2012

23. Lipsman N, Ellis M, Lozano AM: Current and future indications for deep brain stimulation in pediatric populations. Neurosurg Focus 29:E2, 2010

24. Lumsden DE, Ashmore J, Charles-Edwards G, Selway R, Lin JP, Ashkan K: Observation and modeling of deep brain stimulation electrode depth in the pallidal target of the developing brain. World Neurosurg 83:438-446, 2015

25. Lumsden DE, Kaminska M, Ashkan K, Selway R, Lin JP: Deep brain stimulation for childhood dystonia: Is 'where' as important as in 'whom'? Eur J Paediatr Neurol 21:176-184, 2017

26. Lumsden DE, Kaminska M, Gimeno H, Tustin K, Baker L, Perides S, et al: Proportion of life lived with dystonia inversely correlates with response to pallidal deep brain stimulation in both primary and secondary childhood dystonia. Dev Med Child Neurol 55:567-574, 2013

27. Lumsden DE, Kaminska M, Tustin K, Gimeno H, Baker L, Ashkan K, et al: Battery life following pallidal deep brain stimulation (DBS) in children and young people with severe primary and secondary dystonia. Childs Nerv Syst 28:10911097, 2012

28. Marks W, Bailey L, Sanger TD: PEDiDBS: The pediatric international deep brain stimulation registry project. Eur $\mathbf{J}$ Paediatr Neurol 21:218-222, 2017 
29. Marks WA, Honeycutt J, Acosta F, Reed M: Deep brain stimulation for pediatric movement disorders. Semin Pediatr Neurol 16:90-98, 2009

30. McBeth PB, Louw DF, Rizun PR, Sutherland GR: Robotics in neurosurgery. Am J Surg 188 (4A Suppl):68S-75S, 2004

31. Mehrkens JH, Borggraefe I, Feddersen B, Heinen F, Bötzel $\mathrm{K}$ : Early globus pallidus internus stimulation in pediatric patients with generalized primary dystonia: long-term efficacy and safety. J Child Neurol 25:1355-1361, 2010

32. Miyagi Y, Koike Y: Tolerance of early pallidal stimulation in pediatric generalized dystonia. J Neurosurg Pediatr 12:476-482, 2013

33. Olaya JE, Christian E, Ferman D, Luc Q, Krieger MD, Sanger TD, et al: Deep brain stimulation in children and young adults with secondary dystonia: the Children's Hospital Los Angeles experience. Neurosurg Focus 35(5):E7, 2013

34. Owen T, Gimeno H, Selway R, Lin JP: Cognitive function in children with primary dystonia before and after deep brain stimulation. Eur J Paediatr Neurol 19:48-55, 2015

35. Parr JR, Green AL, Joint C, Andrew M, Gregory RP, Scott $\mathrm{RB}$, et al: Deep brain stimulation in childhood: an effective treatment for early onset idiopathic generalised dystonia. Arch Dis Child 92:708-711, 2007

36. Rughani AI, Lozano AM: Surgical treatment of myoclonus dystonia syndrome. Mov Disord 28:282-287, 2013

37. Salpietro V, Perez-Dueñas B, Nakashima K, San AntonioArce V, Manole A, Efthymiou S, et al: A homozygous lossof-function mutation in PDE2A associated to early-onset hereditary chorea. Mov Disord 33:482-488, 2018

38. Sanger TD, Chen D, Fehlings DL, Hallett M, Lang AE, Mink JW, et al: Definition and classification of hyperkinetic movements in childhood. Mov Disord 25:1538-1549, 2010

39. Starr PA, Markun LC, Larson PS, Volz MM, Martin AJ, Ostrem JL: Interventional MRI-guided deep brain stimulation in pediatric dystonia: first experience with the ClearPoint system. J Neurosurg Pediatr 14:400-408, 2014

40. Tsering D, Tochen L, Lavenstein B, Reddy SK, Granader Y, Keating RF, et al: Considerations in deep brain stimulation (DBS) for pediatric secondary dystonia. Childs Nerv Syst 33:631-637, 2017

41. Valldeoriola F, Regidor I, Mínguez-Castellanos A, Lezcano E, García-Ruiz P, Rojo A, et al : Efficacy and safety of pallidal stimulation in primary dystonia: results of the Spanish multicentric study. J Neurol Neurosurg Psychiatry 81:6569, 2010

42. Varma TR, Eldridge P: Use of the NeuroMate stereotactic robot in a frameless mode for functional neurosurgery. Int J Med Robot 2:107-113, 2006

43. Vidailhet M, Vercueil L, Houeto JL, Krystkowiak P, Benabid AL, Cornu P, et al : Bilateral deep-brain stimulation of the globus pallidus in primary generalized dystonia. $\mathbf{N}$ Engl J Med 352:459-467, 2005

44. von Langsdorff D, Paquis P, Fontaine D: In vivo measurement of the frame-based application accuracy of the Neuromate neurosurgical robot. J Neurosurg 122:191-194, 2015

45. Wang MY, Goto T, Tessitore E, Veeravagu A: Introduction. Robotics in neurosurgery. Neurosurg Focus 42(5):E1, 2017

\section{Disclosures}

Medtronic has supported meetings about dystonia for patients and professionals in Hospital Sant Joan de Déu Barcelona. Dr. Candela reports receiving compensation from Medtronic for attending courses and congresses as well as financial support for research and clinical efforts.

\section{Author Contributions}

Conception and design: Candela, Pérez-Dueñas. Acquisition of data: Candela, Vanegas, Darling, Ortigoza-Escobar, Muchart, Pérez-Dueñas. Analysis and interpretation of data: Candela, Vanegas, Darling, Ortigoza-Escobar, Pérez-Dueñas. Drafting the article: Candela, Pérez-Dueñas. Critically revising the article: Vanegas, Darling, Ortigoza-Escobar, Alamar, Muchart, Climent, Ferrer, Rumià. Reviewed submitted version of manuscript: all authors. Approved the final version of the manuscript on behalf of all authors: Candela. Study supervision: Ferrer, Rumià, PérezDueñas.

\section{Supplemental Information \\ Videos}

Video 1. https://vimeo.com/271459080.

Video 2. https://vimeo.com/271459216.

\section{Previous Presentations}

Part of this paper was presented as a poster at the WSSFN Congress in Berlin, Germany, June 26-27, 2017.

\section{Correspondence}

Santiago Candela: Hospital Sant Joan de Déu Barcelona, Barcelona, Spain.scandela@sjdbarcelonahospital.org. 